\title{
Deficiency of protein-L-isoaspartate (D-aspartate) 0 -methyl- transferase expression under endoplasmic reticulum stress promotes epithelial mesenchymal transition in lung adenocarcinoma
}

\author{
Masahiro Yamashita', Masahito Ogasawara², Yasushi Kawasaki ${ }^{3}$, Miyuki Niisato ${ }^{1}$, \\ Heisuke Saito ${ }^{1}$, Shuya Kasai ${ }^{4,5}$, Chihaya Maesawa ${ }^{4}$, Makoto Maemondo ${ }^{1}$ and Kohei \\ Yamauchi, ${ }^{1,6}$ \\ ${ }^{1}$ Department of Pulmonary Medicine, Allergy and Immunological Diseases, School of Medicine, Iwate Medical University, \\ Morioka, Iwate, Japan \\ ${ }^{2}$ Department of Pharmacology, Graduate School of Medicine, Ehime University, Toon, Ehime, Japan \\ ${ }^{3}$ Department of Health Chemistry, School of Pharmacology, Iwate Medical University, Shiwa, Iwate, Japan \\ ${ }^{4}$ Department of Cancer Biology, Iwate Medical University, Shiwa, Iwate, Japan \\ ${ }^{5}$ Department of Biomolecular Sciences, Graduate School of Life Sciences, Tohoku University, Sendai, Miyagi, Japan \\ ${ }^{6}$ Geriatric Health Services Facilities, Keiyu, Morioka, Japan \\ Correspondence to: Masahiro Yamashita, email: yamam@iwate-med.ac.jp \\ Keywords: lung adenocarcinoma; PIMT; endoplasmic reticulum stress; epithelial mesenchymal transition; hypoxia-inducible factor la \\ Received: August 01, $2016 \quad$ Accepted: January 19, $2018 \quad$ Published: January 27, 2018 \\ Copyright: Yamashita et al. This is an open-access article distributed under the terms of the Creative Commons Attribution License \\ 3.0 (CC BY 3.0), which permits unrestricted use, distribution, and reproduction in any medium, provided the original author and \\ source are credited.
}

\section{ABSTRACT}

A prognostic association between the novel chaperone protein-L-isoaspartate (D-aspartate) 0 -methyltransferase (PIMT) and lung adenocarcinoma has recently been reported. Here, we evaluated the functional roles of PIMT in the progression of lung adenocarcinoma. PIMT expression was detectable in 6 lung adenocarcinoma cell lines: A549, H441, H460, H1650, Calu 1, and Calu 6 cell lines. In A549 and H441 cells, knockdown by PIMT using silencing RNA of PIMT (si-PIMT) and/or small hairpin-RNA (sh-PIMT) induced a decrease in the expression of E-cadherin with an increase in vimentin expression, indicating that the epithelial to mesenchymal transition (EMT) was induced. Cell mobility, including migration and invasion capability, was increased in sh-PIMT A549 stable and si-PIMT H441 cells compared to in control cells. Endoplasmic reticulum (ER) stress, such as Thapsigargin (Tg) stress and hypoxia, induced EMT in A549 cells but not in other cell types, with an increase in GRP78 expression, whereas overexpression of PIMT reduced the EMT and cell invasion under stress conditions. The expression of hypoxia inducible factor-1 alpha (HIF1a) and Twist increased in sh-PIMT A549 and si-PIMT H441 cells, and Tg stress increased HIF1a expression levels in A549 cells in a dose-dependent manner. Moreover, LW6, an HIF1a inhibitor, reduced EMT, cancer invasion, and the levels of Twist in sh-PIMT A549 cells. Our results indicate that deficiency of supplemental PIMT expression under ER stress facilitates EMT and cell invasion in some cell types of lung adenocarcinoma. 


\section{INTRODUCTION}

Lung cancer is a major global health concern, and non-small cell lung cancer is the most common disease type [1]. Despite advances in chemotherapy, radiation, and surgery, the prognosis of lung cancer remains unsatisfactory [2]. Carcinogenesis, tumorigenesis, invasion, and distant metastasis of cancer cells are involved in cancer development [3, 4]. Various stresses, such as oxidant stress, malnutrition, and hypoxia within tissue, are exerted on cancer cells through these processes and can cause the accumulation of unfolded proteins in the ER [5-7]. Molecular chaperones can fold various types of unfolded proteins induced by ER stress. A large number of studies has shown that molecular chaperones show increased expressed in cancer cells, and it has been speculated that molecular chaperones facilitate the survival of cancer cells via anti-apoptotic effects $[8,9]$.

Recently, concern has increased regarding the pathogenic association between cancer and protein L-isoaspartyl (D-aspartyl) $O$-methyltransferase (PIMT), which functions as a chaperone for the conversion of isomerized L-isoaspartyl and $\mathrm{D}$-aspartic acid residues into L-Asp [10-13]. Lapointe et al. found that expression levels of PIMT are inversely correlated with stage progression in astrocytic tumors [10]. In contrast, Lee et al. showed that higher PIMT expression is associated with poor prognoses for breast and lung cancers [11]. They demonstrated mutual interference between PIMT and wild-type p53 expression in vitro using various cell lines, and found that inductive expression of PIMT exerts an anti-apoptotic and carcinogenic effect by inhibiting the wild-type p53 pathway. We previously reported that strong expression of PIMT was immunohistochemically detected in approximately half of patients with lung adenocarcinoma and an independent predictor of poor prognosis for lung adenocarcinoma [13]. In addition, strong PIMT expression was correlated with higher levels of $78-\mathrm{kDa}$ glucose-regulated protein (GRP78), a marker of ER stress, rather than p53 expression. However, it has remains unclear whether the inconsistent prognostic values of higher PIMT expression are related to specific types of cancers and the roles of PIMT in multiple processes during the development of each type of cancer.

In the present study, we evaluated the functional roles of PIMT in the disease progression of lung adenocarcinoma using several cell lines, based on the hypothesis that PIMT expression participates in cancer progression of lung adenocarcinoma rather than carcinogenesis. We found that inhibition of PIMT expression using small interference (si)-RNA and small hairpin (sh)-RNA resulted in epithelial mesenchymal tradition (EMT) in some of the cell lines. Our results provide insight into the pathogenesis of lung adenocarcinoma.

\section{RESULTS}

\section{PIMT expression in cancer cell lines and epithelial properties in si-PIMT cancer cells}

We explored the expression of PIMT in 6 lung adenocarcinoma cells lines: A549, H441, H460, H1650, Calu 1, and Calu 6 cells (Figure 1A and 1B). A549 and H441 cells showed lower levels of PIMT expression than the other 4 cell lines. GRP78 expression was detected in H460 cells, but weakly expressed in the remaining lineages. p53 expression was remarkably decreased in H1650, Calu 1, and Calu 6 cells, while expression was detected in A549, H441, and H460 cells. Vimentin expression was increased in A549 and H460 cells compared to in other cells, while H441 and H1650 cells showed higher levels of E-cadherin expression. Two antisense PIMT si-RNAs (J-010000-05-0002 and J-01000007-0002) induced a significant decrease in E-cadherin expression and increase in the expression of vimentin in A549 and H441 cells, indicating that EMT occurred (Figure 1C-1F). H1650 cells showed a significant decrease in E-cadherin and vimentin expression (Figure 1I and $1 \mathrm{~J}$ ). No change in vimentin and E-cadherin expression was observed in the remaining 3 cell lines, which showed a higher intensity of PIMT expression (Figure 1G, 1H, and $1 \mathrm{~K}-1 \mathrm{~N})$. Si-PIMT H441 cells morphologically showed minimal changes, when compared with si-control cells, although si-PIMT A549 cells showed weaker connection with neighboring cells relative to si-control A549 ones (Supplementary Figure 1).

\section{Mobility capability in si-RNA PIMT A549, H441, and $\mathrm{H} 1650$ cells}

Next, we estimated mobility capability in si-PIMT A549, H441 and H1650 cells in a Matrigel gel assay. SiPIMT A549 and H441 cells showed increased migration and invasion capabilities relative to si-control cells, although si-PIMT H1650 showed no significant difference (Figure 2). These results indicated that PIMT expression is correlated to the conservation of epithelial properties and mobility in A549 and H441 cells.

\section{Epithelial and mobility properties on sh-RNA PIMT A549 lines}

Further, we constructed sh-PIMT and sh-control cells in the A549 cell line. Consistently, sh-PIMT A549 cells showed a clearer decrease in E-cadherin expression and increase in the expression of vimentin compared to control cells (Figure 3A and 3B). Sh-PIMT A549 cells showed spindle-like shapes compared with the shcontrol (Figure 3C and 3D). Migratory and invasive capabilities were significantly increased in sh-PIMT A549 cells compared to in sh-control cells (Figure 3E- 
3G). In contrast, sh-PIMT A549 cells showed a significant decrease in cell proliferation following treatment with $8.0 \mu \mathrm{g} / \mathrm{mL}$ cisplatin compared to sh-control cells (Figure $3 \mathrm{H})$. Although TGF $\beta$ has been reported to induce EMT in A549 cells, the expression of TGF $\beta$ was increased in A549 sh-control cells compared to in A549 sh-PIMT cells, indicating that PIMT knockdown-induced EMT in A549 occurred independently of TGF $\beta$ [14].

\section{Response of lung adenocarcinoma cell lines to Thapsigargin and tunicamycin}

Next, we explored whether the conservative epithelial effects by PIMT expression are attributable to standard chaperone functions using two types of ER stress inducers, $\mathrm{Tg}$ and $\mathrm{Tn}$. Over a range of $\mathrm{Tg}$ concentrations from $1.0 \times 10^{-4}$ to $0.5 \mu \mathrm{M}$, GRP78 protein levels in A549, H441, and H1650 cells were increased in a dose- dependent manner (Figure 4A-4I). In contrast, H460 cells showed no change in GRP78 in response to Tg (Figure 4J and 4L). PIMT expression was slightly increased in A549 and H441 cells at $\mathrm{Tg}$ concentrations above $1.0 \times 10^{-2}$ $\mu \mathrm{M}$ relative to baseline levels, although no change was observed in H1650 cells. PIMT expression in H460 cells was decreased at $\mathrm{Tg}$ concentrations above $1.0 \times 10^{-2} \mu \mathrm{M}$. Vimentin expression showed minimal changes in all cell lines. E-cadherin levels in A549 cells were significantly decreased compared to baseline at $\mathrm{Tg}$ concentrations above $0.1 \mu \mathrm{M}$, although the levels were increased compared to those at baseline at a concentration of $5.0 \times$ $10^{-2} \mu \mathrm{M}$ of $\mathrm{Tg}$. In contrast, E-cadherin levels showed no change in H441 and H460 cells in response to Tg stress, and was somewhat increased in H1640 cells. Tg stress had a limited influence on p53 expression (Figure 4A and 4B). In addition, Tn did not decrease E-cadherin expression in A549 and H441 cells, although Tn induced an increase

B
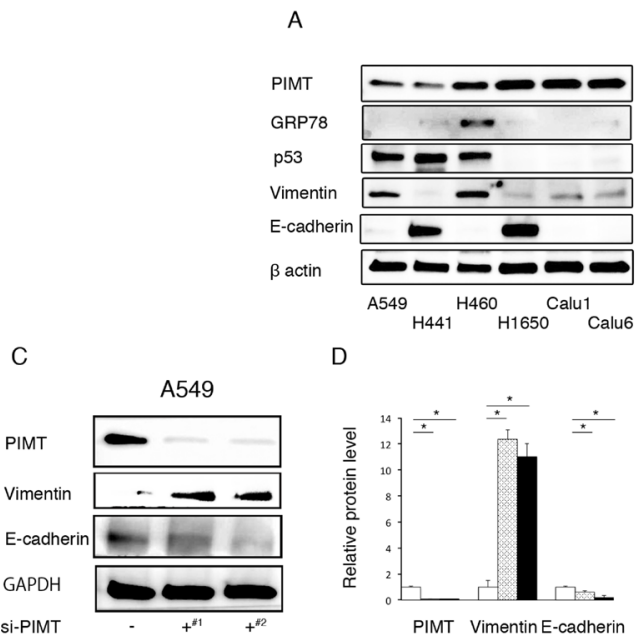

D

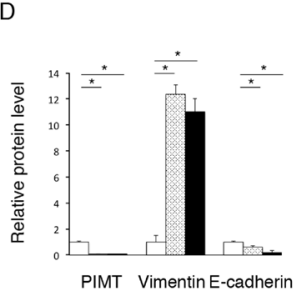

$E$

PIMT
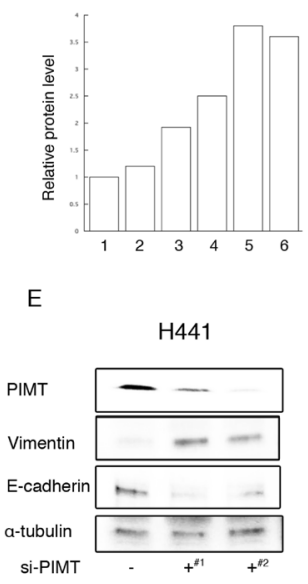

I
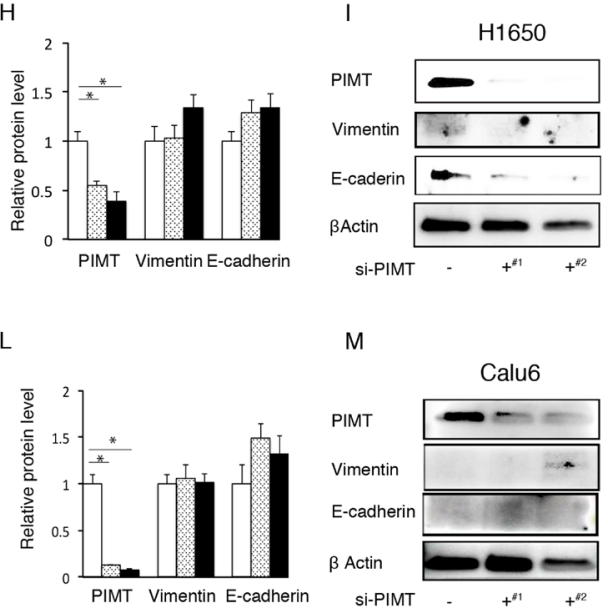

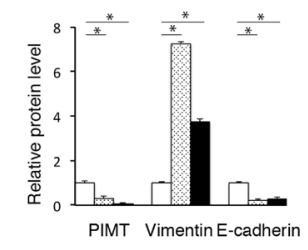

$J$

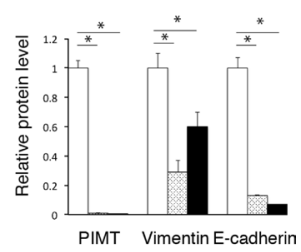

$\mathrm{N}$

F

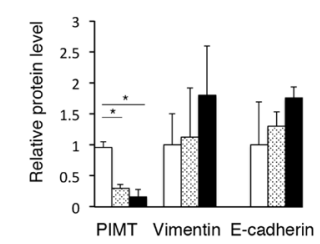

Figure 1: PIMT expression in cancer cell lines and epithelial properties in si-PIMT cancer cells. (A) Immunoblotting of PIMT, GRP78, p53, vimentin, and E-cadherin in 6 lung adenocarcinoma cell lines: A549, H441, H460, H1650, Calu 1, and Calu 6. (B) Expression levels of PIMT in the six cell lines. (C, D) Immunoblot and intensity levels of PIMT, vimentin, and E-cadherin in A549 cells interfered by PIMT si-RNA anti-sense (J-010000-05-0002 ${ }^{\# 1}$ and J-010000-07-0002 ${ }^{\# 2}$ ). Immunoblot and intensity levels of vimentin, E-cadherin, and PIMT in H441 (E, F), H1650 (G, H), H460 (I, J), Calu1 (K, L) and Calu6 cells (M, N) interfered by PIMT si-RNA antisense $\left(\mathrm{J}-010000-05-0002^{\star}\right.$ and J-010000-07-0002§). ${ }^{*}$ indicates $p<0.05$. 
in GRP78 expression in these cells in a dose-dependent manner (Supplementary Figure 2). Taken together, partial EMT was detectable only for the combination of A549 cells and $\mathrm{Tg}$.

\section{Overexpression of PIMT protect Tg-induced EMT in A549 cells}

Moreover, we explored whether overexpression of PIMT relieves the decrease in E-cadherin expression of A549 cells induced by $\mathrm{Tg}$ stress (Figure 5A-5C). Transfection using a PIMT vector caused a significant increase in PIMT expression compared to that in the control transfected with an empty vector (Figure 5A and 5B). Overexpression of PIMT recovered the protein level of E-cadherin that was decreased by $0.1 \mu \mathrm{M}$ of Tg stress and increased E-cadherin levels to near baseline without Tg stress (Figure 5A and 5C).

\section{Supplemental expression of PIMT reduces EMT and cell invasion in A549 cells induced by hypoxia}

Next, we explored whether hypoxic conditions can induce EMT in A549 and H441 cells. Under hypoxic conditions $\left(1 \% \mathrm{O}_{2}\right.$ concentration), the expression of GRP78 in A549 but not in H441 cells showed a significant increase in a time-dependent manner, indicating that hypoxic conditions induce ER stress in A549 cells (Figure 6A and 6B, and Supplementary Figure 3). Furthermore, we tested whether overexpression of PIMT reduces EMT in A549. Overexpression of PIMT under normoxic conditions induced a decrease in vimentin expression with an increase in E-cadherin levels in A549 cells (Figure 6C6F). Similarly, overexpression of PIMT induced a decrease in vimentin expression with an increase in E-cadherin levels in A549 cells induced by $1 \% \mathrm{O}_{2}$ conditions.

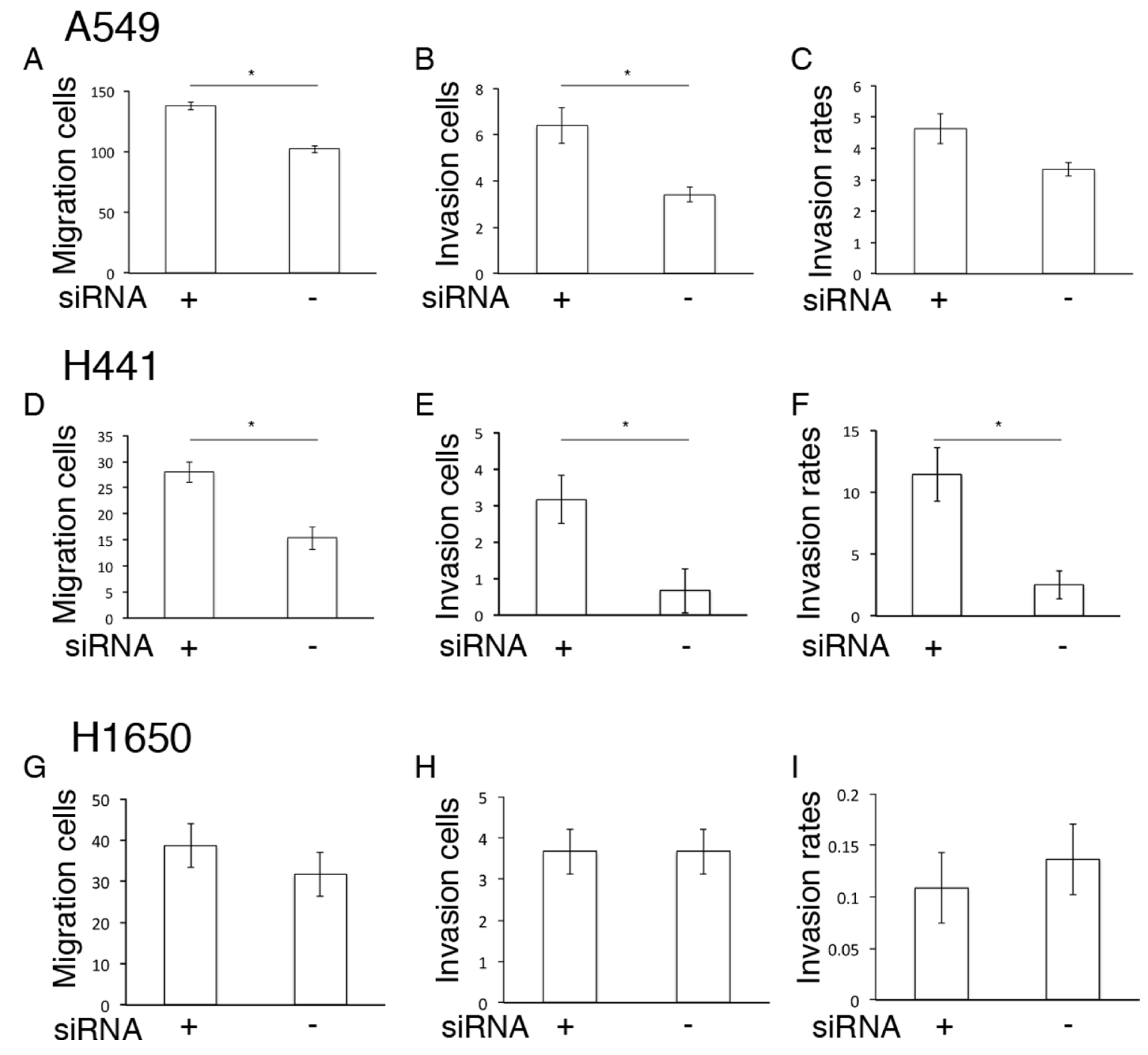

Figure 2: Mobility capability in si-RNA PIMT A549, H441 and $\mathrm{H1650}$ cells. Comparison of migration and invasion capabilities between si-PIMT and si-control A549 cells (A-C), H441 (D-F) and H1650 cells (G-I). *indicates $p<0.05$. 
Moreover, we explored whether PIMT expression is involved in the mobility of A549 cells under hypoxic conditions (Figure 6G-6I). Migration and invasion quantities under hypoxic conditions were significantly decreased by overexpression of PIMT compared to those in the negative control. In addition, invasion rates were also decreased by overexpression of PIMT.

\section{HIF1 $\alpha$ regulates EMT and cell invasion in A549 cells induced by deficiency of PIMT expression under ER stress}

We evaluated which transcription factors participate in EMT and cell invasion in A549 cells induced by ER stress. Compared with sh-control and si-control cells, protein levels in HIF $1 \alpha$ and Twist were higher in sh-PIMT A549 and si-PIMT H441 cells (Figure 7). No difference was detected in HIF1 $\alpha$ expression of the other four cell lines between si-control and si-PIMT cells (Supplementary Figure 4). Slug expression in si-PIMT H441 cells, but not in sh-PIMT A549 cells, was increased relative to control cells, while Snail was expressed in neither A549 nor H441 cells. Zeb-1 was somewhat decreased in sh-PIMT A549 and si-PIMT H441 cells. The relationship between Tg stress and HIF1 $\alpha$ expression in A549 and H441 cells was then explored. Protein levels of HIF1 $\alpha$ increased gradually with increasing concentrations of $\mathrm{Tg}$ in A549 cells, while H441 showed minimal changes in HIF1 $\alpha$ levels (Figure 7). Further, we explored whether LW6, an HIF1 $\alpha$ inhibitor, inhibits EMT of A549 cells induced by Tg stress. LW6 considerably suppressed HIF1 $\alpha$ expression in A549 cells treated with $0.1 \mu \mathrm{M}$ of $\mathrm{Tg}$ in a dose-dependent manner, while protein levels of E-cadherin were gradually increased (Figure 8A and 8B). In addition, LW6 decreased the protein levels of Twist (Figure 8C and 8D). These results indicate that HIF $1 \alpha$ signals are involved in EMT of A549 cells induced by Tg stress. Moreover, we clarified that inhibition of HIF $1 \alpha$ reduces cell mobility in sh-PIMT A549 cells. Compared to the DMSO control, LW6 administration significantly reduced the migration and invasion capabilities of sh-PIMT A549 cells (Figure 8E-8G).

\section{DISCUSSION}

In the present study, we demonstrated that EMT and increased cell mobility of A549 cells were induced by inhibition of PIMT using si-RNA and sh-RNA, as well as Tg stress and hypoxic conditions. Tg stress and hypoxia increased the GRP78 levels of A549 cells in a dose- and time-dependent manner, respectively. The decreased E-cadherin levels induced by Tg and hypoxia were relieved by overexpression of PIMT. These results indicate that PIMT contributes to the conservation of epithelial properties in A549 cells against Tg- and hypoxic stresses. It has been reported that several mediators and/or conditions induce EMT in A549 cells [15-18]. Particularly, TGF $\beta$ is a powerful inducer of EMT in A549 cells [14]. In
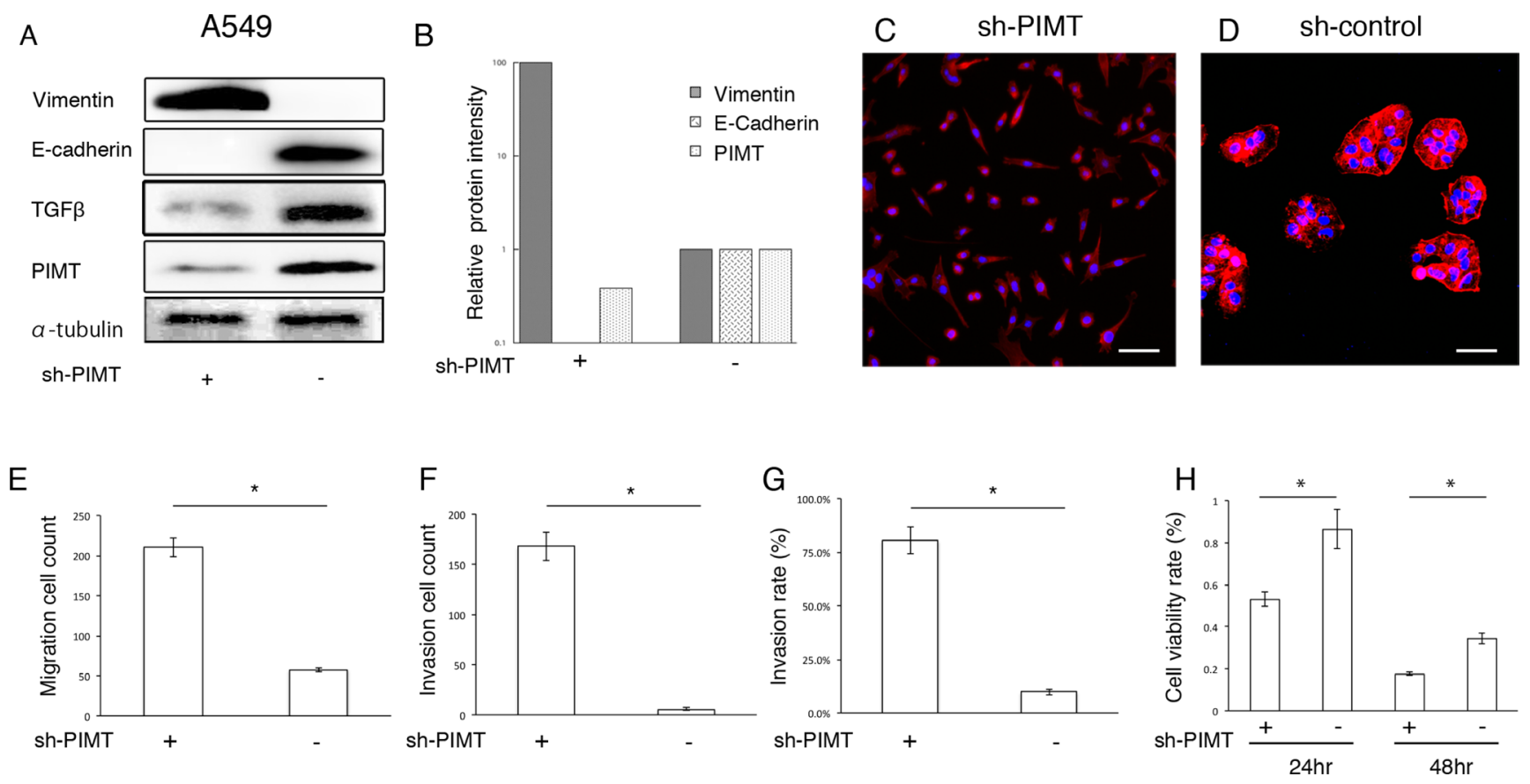

Figure 3: Epithelial properties and mobility capability in sh-PIMT A549 cells. (A, B) Immunoblot and intensity levels of PIMT, vimentin, E-cadherin, and TGF $\beta$ in sh-PIMT and sh-control A549 cells. (C, D) Morphologic differences between sh-PIMT and sh-control A549 cells. Scale bar, $60 \mu \mathrm{m}$. (E-G) Differences in migration and invasion capabilities between sh-PIMT and sh-control A549 cells. (H) Differences in proliferation rate between A549 sh-PIMT and sh-control cells. A549 cells were treated with $8.0 \mu \mathrm{g} / \mathrm{mL}$ of cisplatin. ${ }^{*}$ indicates $p<0.05$. 
the present study, however, inhibited expression of PIMT was related to a decrease in TGF $\beta$, indicating that EMT related to PIMT inhibition occurs independently of TGF $\beta$.

The remaining cell lines did not show similar responses to the inhibition of PIMT by si-RNA, Tg, and hypoxic stresses. The inhibition of PIMT expression by si-RNA also facilitated EMT and cell mobility in H441 similarly to in A549 cells, and GRP78 levels were increased in H441 cells by Tg stress. In H1650 cells, the decreased levels of E-cadherin expression were detectable
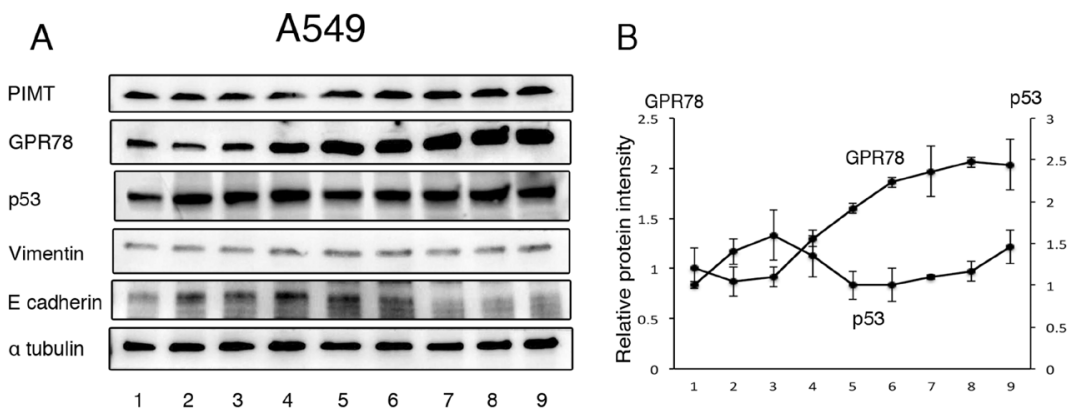

C

D

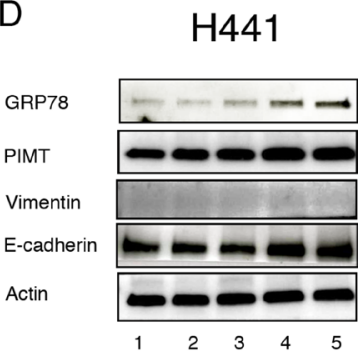

G

H1650

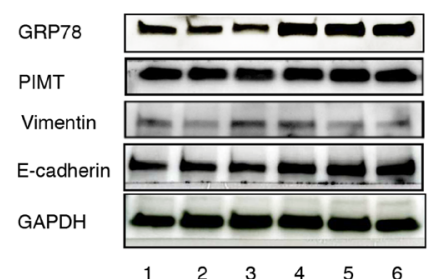

J

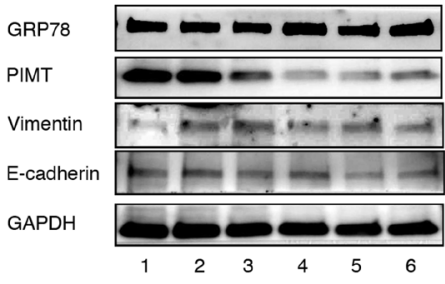

E

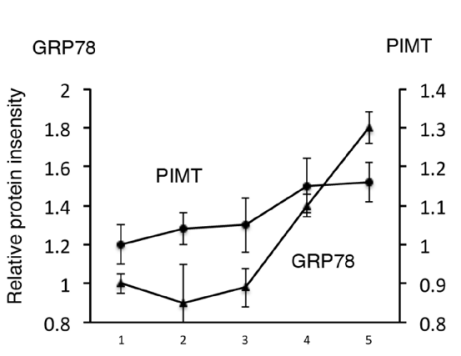

$\mathrm{H}$

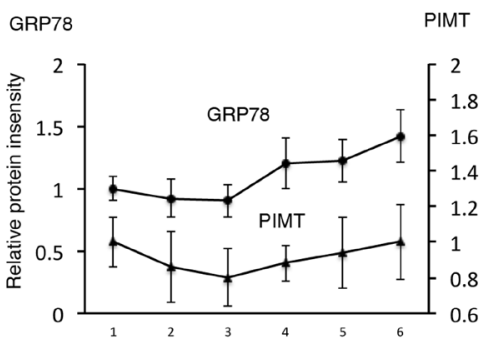

K

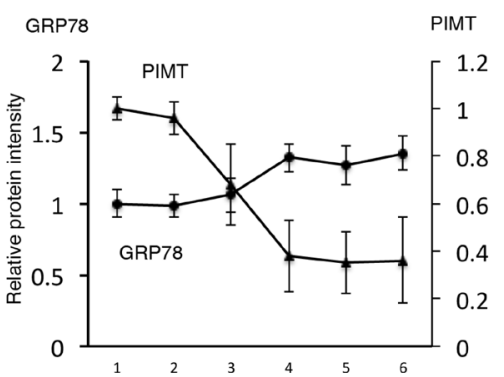

F
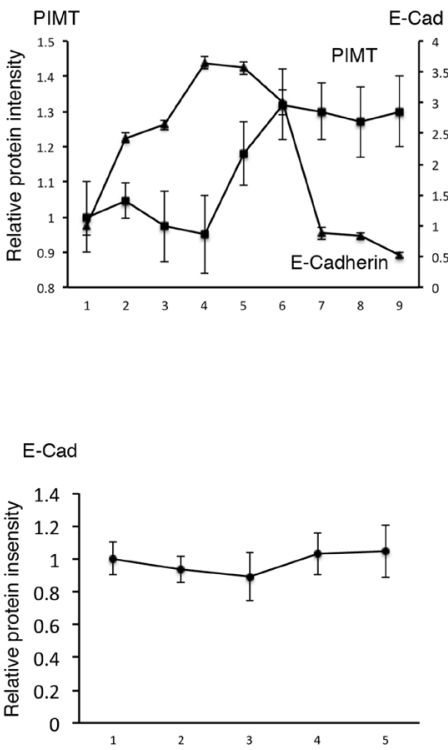

I

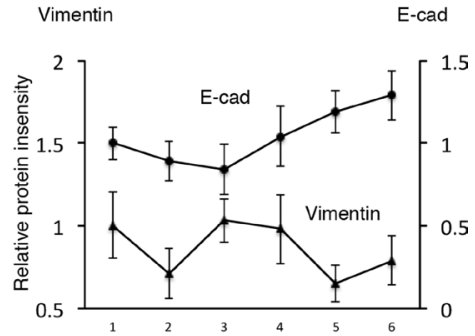

L
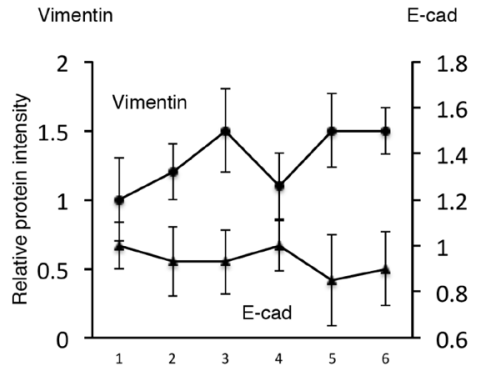

Figure 4: Response of lung adenocarcinoma cell lines to Thapsigargin. (A) Immunoblotting of GRP78, PIMT, p53, vimentin, and E-cadherin in A549 cells treated with Thapsigargin (Tg). Line 1, DMSO; Line 2, $1.0 \times 10^{-4} \mu \mathrm{M}$ of Tg; Line 3, $1.0 \times 10^{-3} \mu \mathrm{M}$ of Tg; Line 4, $5.0 \times 10^{-3} \mu \mathrm{M}$ of Tg; Line 5, $1.0 \times 10^{-2} \mu \mathrm{M}$ of Tg; Line 6, $5.0 \times 10^{-2} \mu \mathrm{M}$ of Tg; Line 7, $0.1 \mu \mathrm{M}$ of Tg; Line 8, $0.2 \mu \mathrm{M}$ of Tg; Line 9, 0.5 $\mu \mathrm{M}$ of Tg. (B) Intensity of GRP78 and p53 in A549 cells treated with Tg. (C) Intensity of PIMT and E-cadherin in A549 cells treated with Tg. Immunoblotting and relative intensity of GRP78, PIMT, vimentin, and E-cadherin in H441 (D-F), H1650 (G-I), and H1650 (J-L) cells treated with Tg. Line 1, DMSO; Line 2, $1.0 \times 10^{-4} \mu \mathrm{M}$ of Tg; Line 3, $1.0 \times 10^{-3} \mu \mathrm{M}$ of Tg; Line 4, $1.0 \times 10^{-2} \mu \mathrm{M}$ of Tg; Line 5, 0.1 $\mu \mathrm{M}$ of Tg; Line 6, $1.0 \mu \mathrm{M}$ of Tg. 
A

A549

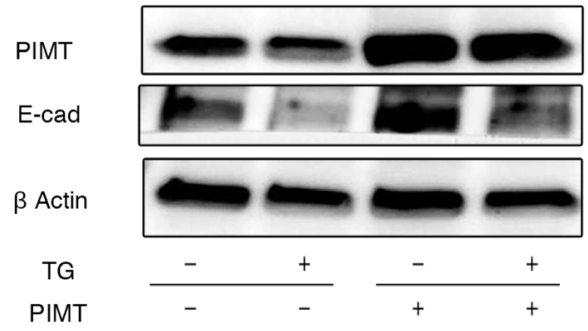

B

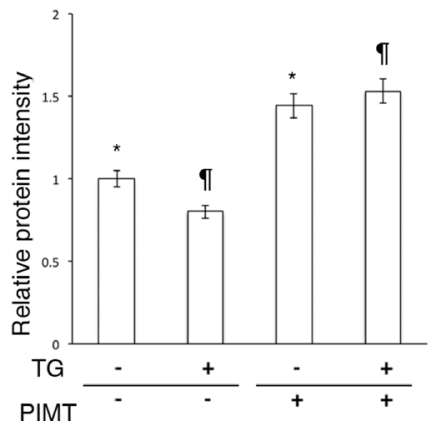

C

E-cadherin

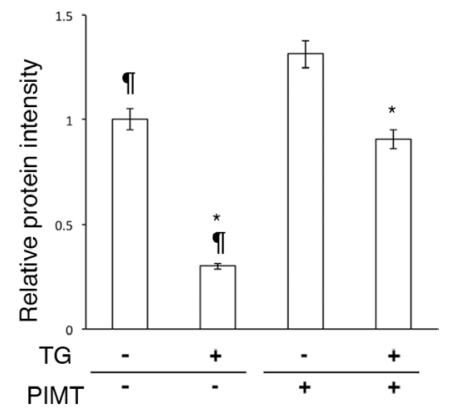

Figure 5: Supplemental expression of PIMT reduces EMT and cell invasion in A549 cells induced by Thapsigargin. (A) Immunoblotting of PIMT and E-cadherin in A549 cells treated with $0.1 \mu \mathrm{M}$ of Tg, and PIMT expression and empty vectors. (B, C) Intensity of PIMT and E-cadherin in A549 cells treated with Tg, and PIMT expression and empty vectors. "indicates $p<0.05$, " indicates $p<0.05$.

A

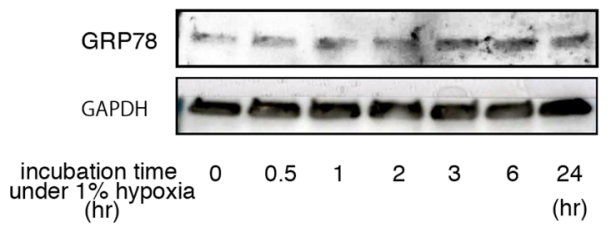

D

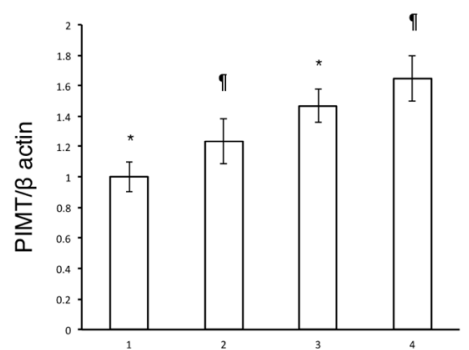

G

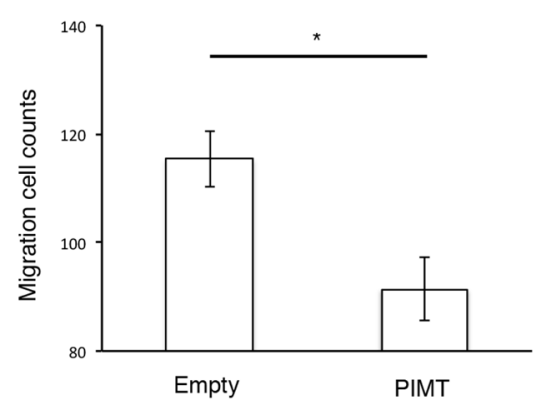

B

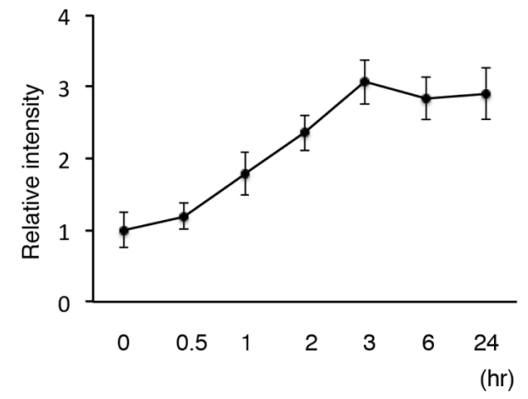

E

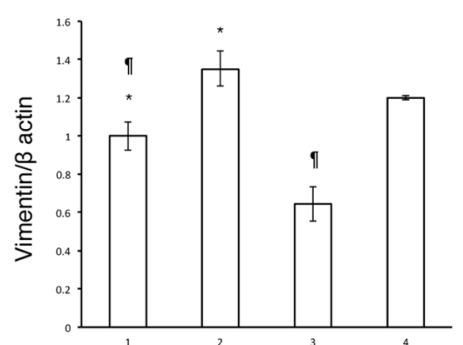

$\mathrm{H}$

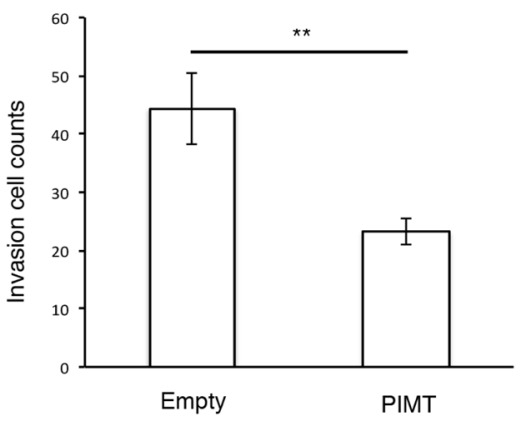

C PIMT

Vimentin

E-cadhein

$\beta$ actin

$\begin{array}{llll}\text { Oxic condition } & 21 \% \quad 1 \% & \frac{21 \% \quad 1 \%}{+} \\ \text { PIMT } & -\end{array}$

F

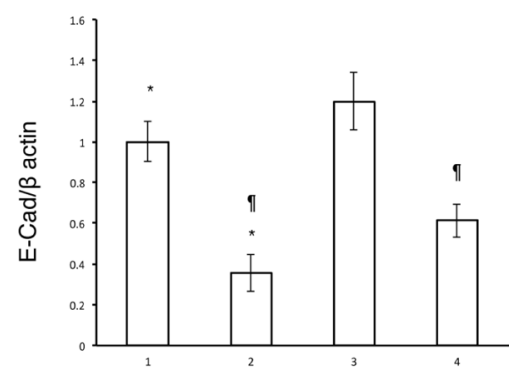

I

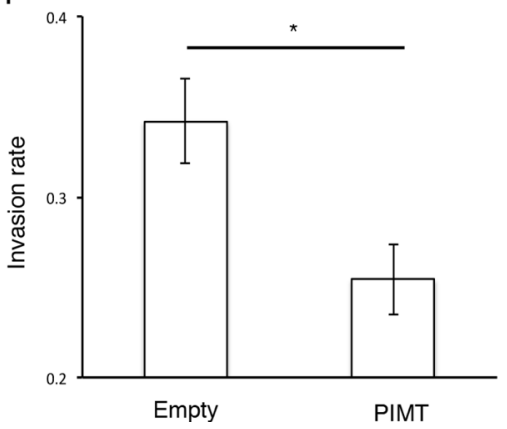

Figure 6: Supplemental expression of PIMT reduces EMT and cancer invasion in A549 cells induced by hypoxic conditions. (A, B) Immunoblotting and relative intensity of GRP78 in A549 cells under normal hypoxic $\left(1 \% \mathrm{O}_{2}\right)$ conditions. (C) Immunoblotting of PIMT, vimentin, and E-cadherin in A549 cells under normal $\left(21 \% \mathrm{O}_{2}\right)$ and hypoxic $\left(1 \% \mathrm{O}_{2}\right)$ conditions treated with and without PIMT vector. (D-F) Intensity of PIMT, vimentin, and E-cadherin in A549 cells treated with and without PIMT vector. Line 1: normoxia + empty vector, Line 2: hypoxia + empty vector, Line 3: normoxia + PIMT vector, Line 4: hypoxia + PIMT vector. (G) Migration cell count, (H) Invasion cell count, and (I) Invasion rate in A549 cells under hypoxic conditions with empty and PIMT vector. "indicates $p$ $<0.05,{ }^{* *}$ indicates $p<0.01$ and ${ }^{\mathrm{I}}$ indicates $p<0.05$. 
by the inhibition of PIMT using si-RNA, although neither vimentin expression nor cell mobility was changed. However, H441 and H1650 cells did not show a decrease in E-cadherin expression by $\mathrm{Tg}$ and/or hypoxia. Our results indicate that PIMT is involved in preserving the epithelial properties of H441 and H1650 cells, but we could not determine other ER stressors that induce EMT in these cell lines. In the remaining three cell lines, E-cadherin expression was not decreased by the inhibition of PIMT using si-RNA. PIMT was not involved in the conservation of epithelial properties in the three cell lines.

We previously found that higher PIMT expression in cancer cells in immunohistochemistry is correlated with poor prognoses in patients with surgically resected lung adenocarcinoma. In the present study, we demonstrated that deficiency of PIMT supplemental expression induced EMT in A549 cells. These findings appear to be inconsistent in terms of the prognostic values of PIMT, as EMT was shown to be related to lymph node and distant metastasis [19]. We formed a rational hypothesis to explain these findings; the cancer cells that establish a compensatory mechanism of PIMT expression against increased ER stresses may remain at primary lesions with conserved epithelial properties and continuously repeat self-proliferation. In contrast, cancer cells that fail to establish a compensatory mechanism of PIMT expression may enter EMT to escape from stresses, followed by invasion into the cancer stroma. Stronger PIMT expression would be beneficial in A549, H441, and H1650 cells, in terms of protection from EMT and cancer invasion, although higher PIMT expression in the other cell lines may be harmful in terms of induction of cancer cell apoptosis and anti-cancer proliferation. Increasing evidence supports that multiple cell lines
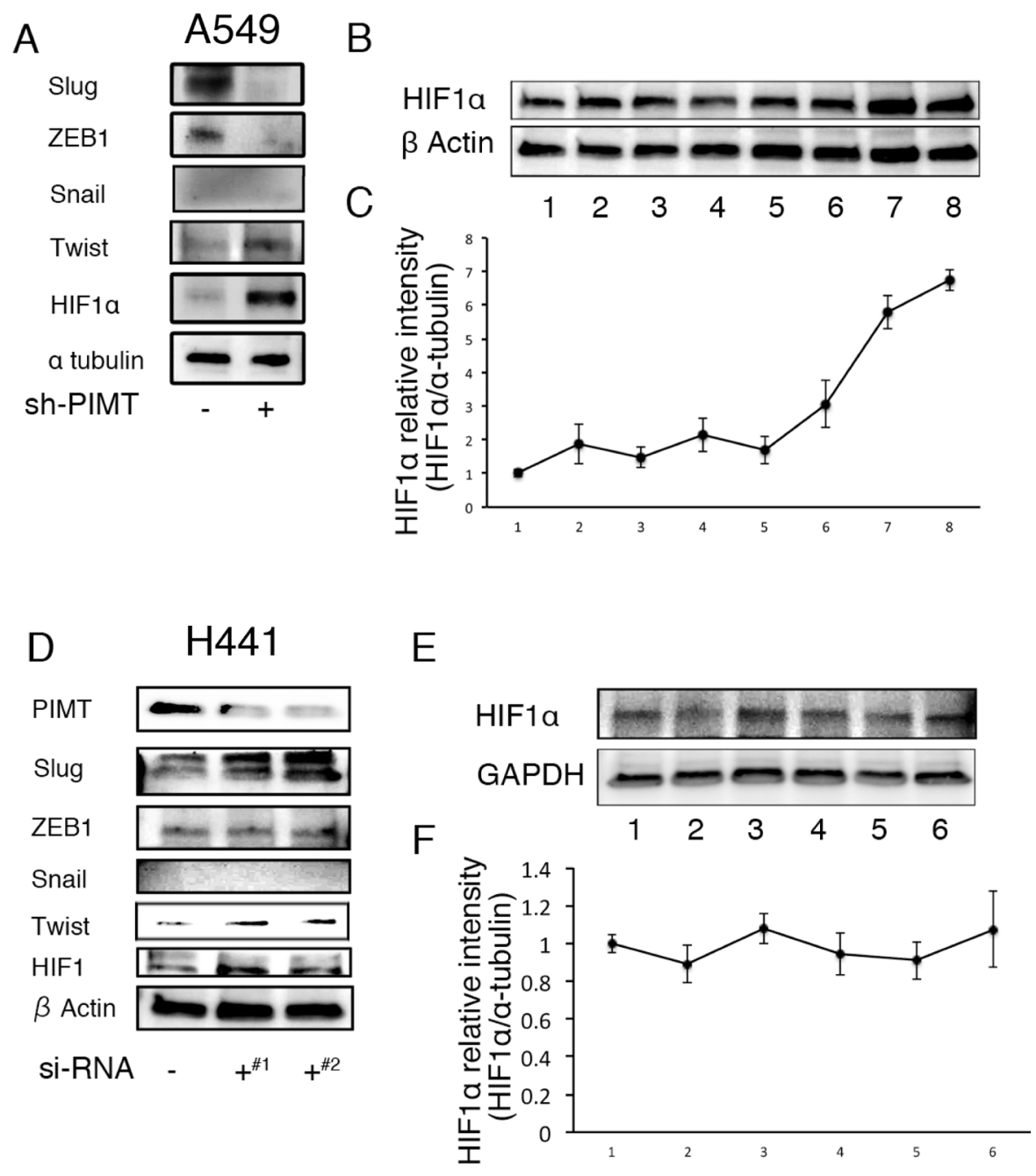

Figure 7: Increased expression of HIF $\alpha$ and/or Twist in A549 and H441 cells induced by the inhibition of PIMT and Thapsigargin. (A) Immunoblotting of Slug, ZEB1, Snail1, Twist, and HIF1 $\alpha$ in A549 sh-PIMT and sh-control cells. (B, C) Immunoblotting and relative intensity of HIF1 $\alpha$ in A549 cells treated with Tg. (D) Immunoblotting of Slug, ZEB1, Snail1, Twist, and HIF $1 \alpha$ in si-control cells and si-PIMT H441 cells. (E, F) Immunoblotting and relative intensity of HIF $1 \alpha$ in H441 cells treated with Tg. \#1 and \#2 indicates si-RNA of J-010000-05-0002 and J-010000-07-0002, respectively. 
derived from the same histopathological type of cancer can behave differently [20]. In this context, our results indicate the necessity of multiple treatment strategies in lung adenocarcinoma.

Some transcription factors including Slug, Zeb-1, Twist, Snail, and HIF1 $\alpha$, were predicted to be associated with EMT in lung adenocarcinoma based on both immunohistochemistry and in vitro experiments [21$25]$. In the present study, increased expression of HIF $1 \alpha$ and Twist was associated with EMT in A549 and H441 cells induced by PIMT inhibition. In addition, Tg stress increased HIF $1 \alpha$ expression levels in A549 cells in a dosedependent manner. Moreover, the HIF $1 \alpha$ inhibitor reduced EMT, cancer invasion, and the protein levels of Twist in
sh-PIMT A549 cells. These findings indicate that HIF $1 \alpha$ is at least partially involved in PIMT-related EMT in A549 cells via Twist signals. Recent reports provide mechanistic evidence of an association between HIF $1 \alpha$-Twist signals and EMT, thus supporting our findings [26-31]. In particular, some papers demonstrated that HIF $1 \alpha$ directly binds to the proximal promoter site of Twist in chromatin immunoprecipitation assay, and then regulates Twist expression [26, 32]. Chemotherapy agents are generally used to induce the apoptosis of cancer cells as an anticancer therapy. It has been reported that chemotherapy causes ER stress in cancer cells [33]. Thus, cancer chemotherapy may induce EMT of cancer cells. Therefore, inhibiting HIF $1 \alpha$ in combination with chemotherapy may

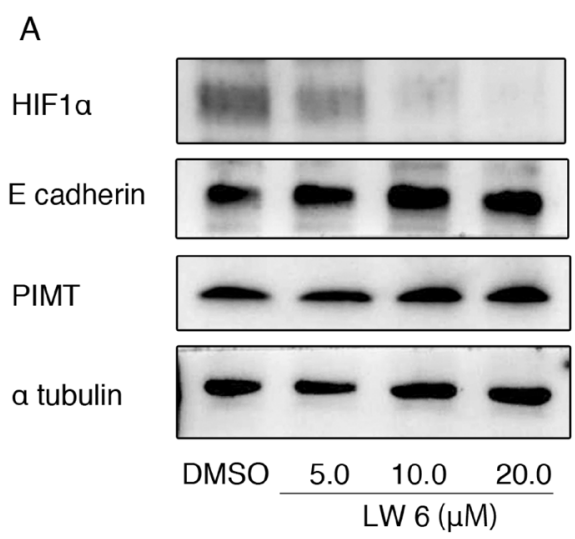

C

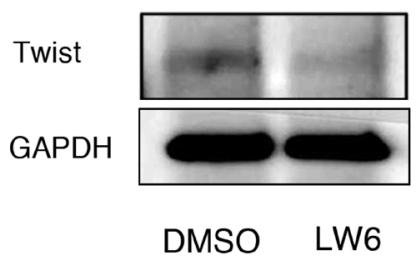

B

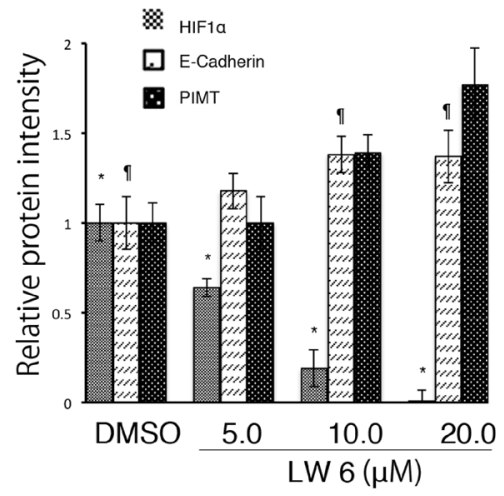

D

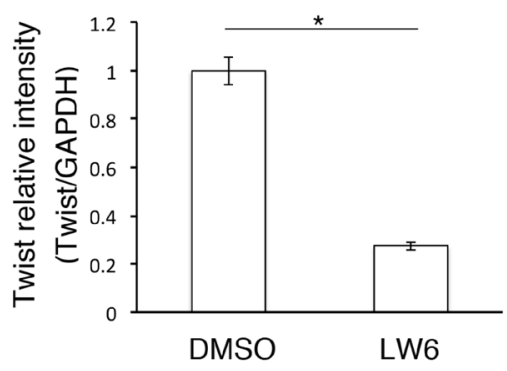

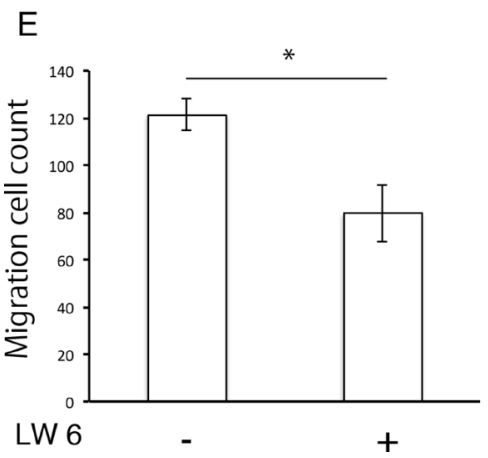
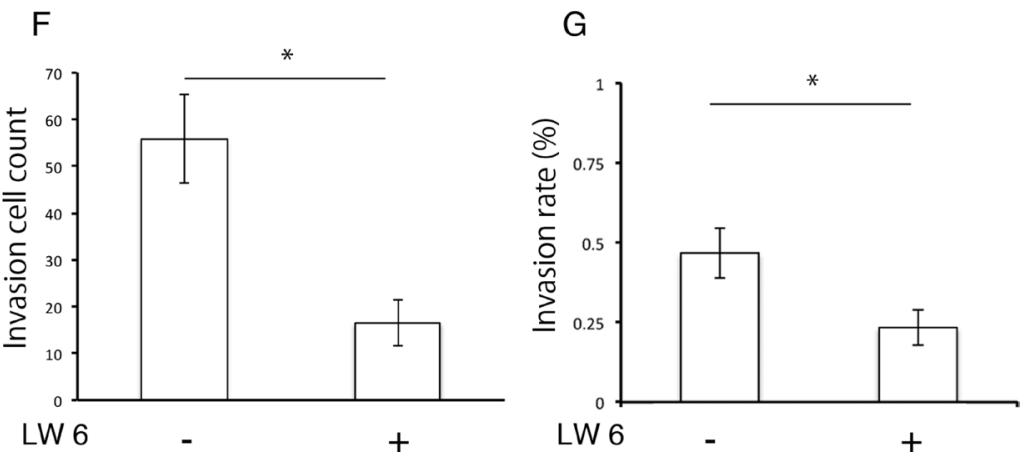

Figure 8: HIF1 $\alpha$ inhibitor decreases EMT and cancer invasion in A549 cells induced by inhibition of PIMT expression. (A and B) Immunoblotting and intensity of HIF1 $\alpha$, E-cadherin, and PIMT in A549 cells treated with LW6 under $0.1 \mu \mathrm{M}$ of Tg. (C and D) Immunoblotting of Twist in sh-PIMT A549 cells treated with LW6. (E) Migration cell count, (F) Invasion cell count, and (G) Invasion rate in A549 sh-PIMT cells treated with LW6. "indicates $p<0.05$ and "indicates $p<0.05$. 
offer a novel treatment target for lung adenocarcinoma to prevent both cancer proliferation and EMT. Further studies are required to determine the mechanism by which PIMT regulates HIF $\alpha$ expression.

Previous studies reported that wild-type p53 generally suppresses EMT in cancer cells, and EMT in cancer cells is caused by the inhibition of wild-type p53 or induction of mutant p53 [34, 35]. The expression of mutant p53 competes with that of wild-type p53 [36]. Lee et al. reported that the inhibitory expression of PIMT using siRNA induced an increase in the expression of wildtype p53 [11]. We found that the intensity of wild-type p53 expression was not clearly correlated with Tg dose. Therefore, involvement of p53 in the mechanism of EMT in A549 cells appeared to be limited, although we could not precisely determine how p53 participated in the EMT.

Ryu et al. previously reported that PIMT showed a significantly increasing correlation with the phosphorylation of ERK1/2 during incubation of MDAMB-231 cells, a breast cancer cell line. Under detached conditions, but not attached conditions, PIMT siRNA blocked the phosphorylation of ERK and expression of EMT proteins, which is inconsistent with the results of the present study [12]. In our study, EMT induced by the inhibition of PIMT was confirmed in multiple cell lines of lung adenocarcinoma. It remains unclear whether the discrepancy is attributable to the difference in cancer types or cell conditions.

We found that the deficiency of compensatory PIMT expression under increased ER stress induces EMT and cancer invasion in lung adenocarcinoma via a HIF1 1 signal. Our results provide insights into the pathogenic perspective of disease progression and indicate the necessity of multiple treatment strategies in lung adenocarcinoma. Inhibition of PIMT and HIF $1 \alpha$ may be a novel treatment target for lung adenocarcinoma.

\section{MATERIALS AND METHODS}

\section{Cell lines}

All cell lines (A549, H441, H460, H1650, Calu 1, and Calu 6) were obtained from the ATCC (Manassas, VA, USA). A549 and H441 cells represented preinvasive stages, while H460, H1650, Calu 1, and Calu 6 cells represented advanced types [37-40]. Cells were grown in RPMI1640 media supplemented with $10 \%$ (v/v) fetal bovine serum (FBS), penicillin, and streptomycin, in a humidified atmosphere of $5 \% \mathrm{CO}_{2}$ and $95 \%$ air at $37^{\circ} \mathrm{C}$. The cells were tested and authenticated by short tandem repeat analysis. Stably transformed cells were selected using geneticin $(1000 \mu \mathrm{g} / \mathrm{mL})$ and collected by cell sorting three times ( $>95 \%$ purified) with a fluorescent protein marker (ZsGreen1) to improve cell purity [41].

\section{Antibodies and reagents}

Anti-PIMT (Abcam PLC, Cambridge, UK, 97446, 1:2000 dilution), anti-E-cadherin (Santa Cruz Biotechnology Inc., Santa Cruz, USA, sc-7870, 1:200 dilution), anti-vimentin (sc-7557, 1:250 dilution), anti- $\alpha$ tubulin (sc-5546, 1:400 dilution), anti-GRP78 (sc-1051, $1: 200$ dilution), anti-p53 (sc-1616, 1:200 dilution), anti- $\beta$ actin (sc-32293, 1:200 dilution), anti-GAPDH (sc-25778), anti-Zeb1 (Atlas Antibodies AB, Stockholm, Sweden, HPA027524, 1:500 dilution), anti-Slug (sc-15391, 1:200 dilution), anti-Twist (Proteintech, Rosemont, IL, USA, 1:500 dilution), anti-Snail1 (Proteintech, 1:1000 dilution), anti-HIF1 $\alpha$ (Novus Biologicals, Minneapolis, USA, NB100-479, 1:1000 dilution), and anti-HIF1 $\alpha$ (Abcam, ab51608, 1:1000 dilution) antibodies were used in this study. Particularly, we used E-cadherin and vimentin to detect epithelial and mesenchymal properties in the cell lines. E-cadherin is a calcium-dependent transmembrane glycoprotein that mediates cell-cell adhesion in the polarized epithelium [42]. The loss of its expression is a hallmark of EMT [43]. Vimentin is a major marker of mesenchymal properties. Thapsigargin ( $\mathrm{Tg}$ ) was purchased from Wako Pure Chemical Industries, Ltd. (Osaka, Japan). Tunicamycin (Tn) was purchased from Sigma-Aldrich (St. Louis, MO, USA). LW6, an inhibitor against HIF1 $\alpha$, was purchased from Merck Millipore (Darmstadt, Germany).

\section{Knockdown and overexpression of PIMT}

Knockdown of PIMT in A549, H441, H460, H1650, Calu 1, and Calu 6 cells and overexpression in A549 cells were carried out in a 6-well format and the cells were transfected according to standard methods. Briefly, cells were seeded in RPMI1640 media containing $10 \%$ FBS with/without antibiotics. After $24 \mathrm{~h}$, the cells were transfected with selected siRNA fragments or vectors in Opti-MEM media (Thermo Fisher Scientific, Waltham, MA, USA) using Lipofectamine RNAiMAX or Lipofectamine 3000 (Invitrogen, Carlsbad, CA, USA). Stealth RNAi siRNA for PIMT (J-010000-05-0002, -06-, -07, -08-; GE Healthcare, Little Chalfont, UK) were transfected with Lipofectamine RNAiMAX according to the manufacturer's instructions. Stealth RNAi siRNA Negative Control Low GC Duplex No.3 (GE Healthcare) was used as a scrambled control throughout the experiment. PIMT knockdown and overexpression were confirmed by western blotting analysis. Each experiment was performed at least in triplicate three times.

\section{Construction of PIMT-Cont shRNA and PIMT- KD shRNA vectors}

We employed a Pol III terminator sequence $\left(5^{\prime}\right.$-TTTTTT-3') in the hairpin loop region as a control for gene silencing experiments to select cells with stable 
expression. This sequence has previously been used as a negative control to generate brain-specific MAPKsilencing transgenic mice [44]. A pENTR ${ }^{\mathrm{TM}} / \mathrm{H} 1 / \mathrm{TO}$ vector (Thermo Fisher Scientific) was used to generate PIMTCont shRNA and PIMT-KD shRNA. To construct PIMTCont, two oligonucleotide sequences, 5'-GTA TGA CAA GCT ACA AGA TTTTTT CTT GTA GCT TGT CAT ACT GC-3' (underlined sequence: Pol III terminator) and 5'-GCA GTA TGA CAA GCT ACA AG AAAAAA TCT TGT AGC TTG TCA TAC TGC-3', were synthesized and annealed for ligation into the $\mathrm{pENTR}^{\mathrm{TM}} / \mathrm{H} 1 / \mathrm{TO}$ vector according to the manufacturer's instructions. The PCMT1Cont vector contained a Pol III terminator sequence in place of the hairpin loop and was designed to prevent expression of the complete PIMT-shRNA. To construct PIMT-KD, two oligonucleotide sequences, 5'-GCA GTA TGA CAA GCT ACA AGA CGAA CTT GTA GCT TGT CAT ACT GC-3' (double underlined sequence: hairpin loop) and 5'-GCA GTA TGA CAA GCT ACA AG TTCG TCT TGT AGC TTG TCA TAC TGC-3, were synthesized and annealed for ligation into $\mathrm{pENTR}^{\mathrm{TM}} / \mathrm{H} 1 / \mathrm{TO}$ according to the manufacturer's instructions.

\section{Construction of PIMT vectors}

A PIMT mRNA expression vector was generated by alternative splicing [41], and a pIRES2-ZsGreen1 vector was used to express PIMT. PCMT1-ER cDNA was amplified by PCR using the forward primer $5^{\prime}-\mathrm{CG}$ GAA TTC ATG CCG GGA GCG CGC AGT GGC GGC AGC-3' (underlined sequence is an EcoRI cleavage site) and reverse primer 5'-GC GGA TCC TTA CAA TTC ATC CCT GGA CCA CTG C-3' (underlined sequence is a BamHI cleavage site). The amplified PCR products were incubated at $37^{\circ} \mathrm{C}$ with EcoRI and BamHI, after which they were purified using a Qiagen gel extraction kit (Hilden, Germany). The purified and excised products were ligated into the EcoRI/BamHI sites of the pIRES2ZsGreen1 expression vector.

\section{Immunoblotting}

Protein aliquots of $15 \mu \mathrm{g}$ each were resolved by SDS polyacrylamide gel (Bio-Rad Laboratories, Hercules, CA, USA) electrophoresis and transferred to polyvinylidene difluoride membranes (Bio-Rad). After washing three times, membranes were incubated with Blocking One (Nacalai Tesque, Inc., Kyoto, Japan) for $1 \mathrm{~h}$ at room temperature, and incubated overnight at $4^{\circ} \mathrm{C}$ with primary antibodies. Thereafter, membranes were washed three times and incubated for $1 \mathrm{~h}$ at room temperature with secondary $\mathrm{Ab}$ [horseradish peroxidaseconjugated species-specific Ab]. Immunoreactive bands were visualized with Clarity Western ECL Substrate (Bio-
Rad). Each experiment was performed at least three times independently.

\section{Cell morphology analysis}

A549 cells with PIMT shRNA or control shRNA were stained with Cytopainter Phalloidin-iFluor 555 conjugate (Abcam, 97446) and DAPI (Dojindo, Tokyo, Japan) to visualize the actin filaments and nuclei.

\section{Cell migration and invasion assay}

Cell migration and invasion were examined by Matrigel (Promega, Fitchburg, WI, USA) invasion assays according to the manufacturer's instructions. Briefly, wild-type A549, H441, and H1650 cells or shPIMT and sh-control stable A549 cells at a density of $2.5 \times 10^{4}$ per well were placed in the upper BD Biocoat Matrigel Invasion Chamber (insert 6.4-mm diameter, 8-mm pore size; BD Bioscience, Franklin Lakes, NJ, USA) in RPMI1640 media without serum. Background migration towards media with $10 \%$ FBS was subtracted. The number of transmigrated cells was counted after $24 \mathrm{~h}$. Each experiment was repeated at least three times independently.

\section{Cell viability assay}

A549 cells with PIMT shRNA and control cells were reseeded at $5 \times 10^{3}$ per well in 96-well plates, and incubated in antibiotic-containing RPMI1640 with $10 \%$ FBS. After $24 \mathrm{~h}$ of incubation, cisplatin $(8.0 \mu \mathrm{g} / \mathrm{mL})$, a key drug in chemotherapy for non-small cell lung carcinoma, was added to each well and incubation was continued for an additional 24 and $48 \mathrm{~h}$. These cells were then used for the proliferation assay, which was measured using Cell Counting Kit-8 (Dojindo). An aliquot of WST8/1-Methoxy PMS solution was added to each well followed by incubation for $2 \mathrm{~h}$ at $37^{\circ} \mathrm{C}$ according to the protocol. Absorbance was measured with a Multiskan FC microplate reader (Thermo Fisher Scientific) at test and reference wavelengths of $450 \mathrm{~nm}$. The percentage of growth is shown relative to untreated controls. Each sample was assayed in duplicate, with each experiment repeated at least three times independently.

\section{Toxicity assay}

To assess whether cell transformation was effectively induced by ER stress initiated by $\mathrm{Tg}$ or $\mathrm{Tn}$, A549, H441, H1650, and H460 cells were seeded into 6-well dishes (Iwaki, Chiba, Japan) at $5.0 \times 10^{5}$ cells/ dish and treated with increasing concentrations of $1.0 \times$ $10^{-4}-1.0 \mu \mathrm{M}$ or $1.0 \times 10^{-4}-1.0 \mu \mathrm{g} / \mathrm{mL}$ for $16 \mathrm{~h}$, respectively. 
To assess whether LW6 could inhibit cell transformation, A549 and H441 cells were seeded into 6-well dishes at $1.0 \times 10^{6}$ cells/dish with $2.0 \mathrm{~mL}$ medium containing LW6 for $16 \mathrm{~h}$.

\section{Statistical analysis}

Statistical significance was evaluated using MannWhitney $U$ test. Statistical analyses were based on SPSS software (SPSS, Inc., Chicago, IL, USA).

\section{ACKNOWLEDGMENTS}

We would like to thank Dr. Tamotsu Sugai for providing precious advise.

\section{CONFLICTS OF INTEREST}

The authors have no conflicts of interest.

\section{FUNDING}

This study was partly supported by KAKEN 20590925 and KAKEN16K08940.

\section{REFERENCES}

1. Vallières E, Shepherd FA, Crowley J, Van Houtte P, Postmus PE, Carney D, Chansky K, Shaikh Z, Goldstraw P; International Association for the Study of Lung Cancer International Staging Committee and Participating Institutions. International Association for the Study of Lung Cancer International Staging Committee and Participating Institutions. The IASLC Lung Cancer Staging Project: proposals regarding the relevance of TNM in the pathologic staging of small cell lung cancer in the forthcoming (seventh) edition of the TNM classification for lung cancer. J Thorac Oncol. 2009; 4:1049-59.

2. Tanaka F, Miyahara R, Kawano Y, Nakagawa T, Shoji T, Wada H. Surgery for non-small cell lung cancer: postoperative survival based on the revised tumornode-metastasis classification and its time trend. Eur J Cardiothorac Surg. 2000; 18:147-55.

3. Higgins KA, D'Amico TA, Berry MF, Sporn T, Boyd J, Kelsey CR. Lymphovascular invasion in non-small-cell lung cancer: implications for staging and adjuvant therapy. J Thorac Oncol. 2012; 7:1141-7.

4. Perlikos F, Harrington KJ, Syrigos KN. Key molecular mechanisms in lung cancer invasion and metastasis: a comprehensive review. Crit Rev Oncol Hematol. 2013; 87:1-11.

5. Su R, Li Z, Li H, Song H, Bao C, Wei J, Cheng L. Grp78 promotes the invasion of hepatocellular carcinoma. BMC Cancer. 2010; 10:20.

6. Zheng HC, Takahashi H, Li XH, Hara T, Masuda S, Guan YF, Takano Y. Overexpression of GRP78 and GRP94 are markers for aggressive behavior and poor prognosis in gastric carcinomas. Hum Pathol. 2008; 39:1042-9.

7. Uramoto $\mathrm{H}$, Sugio $\mathrm{K}$, Oyama $\mathrm{T}$, Nakata $\mathrm{S}$, Ono $\mathrm{K}$, Yoshimastu T, Morita M, Yasumoto K. Expression of endoplasmic reticulum molecular chaperone Grp78 in human lung cancer and its clinical significance. Lung Cancer. 2005; 49:55-62.

8. Hendershot L, Wei J, Gaut J, Melnick J, Aviel S, Argon Y. Inhibition of immunoglobulin folding and secretion by dominant negative BiP ATPase mutants. Proc Natl Acad Sci U S A. 1996; 93:5269-74.

9. Gorbatyuk MS, Gorbatyuk OS. The molecular chaperone GRP78/BiP as a therapeutic target for neurodegenerative disorders: as mini-review. J Genet Syndr Gene Ther. 2013; $4: 128$.

10. Lapointe $\mathrm{M}$, Lanthier J, Moumdjian R, Régina A, Desrosiers RR. Expression and activity of 1-isoaspartyl methyltransferase decrease in stage progression of human astrocytic tumors. Brain Res Mol Brain Res. 2005; 135:93-103.

11. Lee JC, Kang SU, Jeon Y, Park JW, You JS, Ha SW, Bae N, Lubec G, Kwon SH, Lee JS, Cho EJ, Han JW. Protein L-isoaspartyl methyltransferase regulates p53 activity. Nat Commun. 2012; 3:927.

12. Ryu J, Song J, Heo J, Jung Y, Lee SJ, Hong S, Cho JY. Cross-regulation between protein L-isoaspartyl O-methyltransferase and ERK in epithelial mesenchymal transition of MDA-MB-231 cells. Acta Pharmacol Sin. 2011; 32:1165-72.

13. Saito H, Yamashita M, Ogasawara M, Yamada N, Niisato M, Tomoyasu M, Deguchi H, Tanita T, Ishida K, Sugai T, Yamauchi K. Chaperone protein l-isoaspartate (d-aspartyl) O-methyltransferase as a novel predictor of poor prognosis in lung adenocarcinoma. Hum Pathol. 2016; 50:1-10.

14. Kasai H, Allen JT, Mason RM, Kamimura T, Zhang Z. TGFbetal induces human alveolar epithelial to mesenchymal cell transition (EMT). Respir Res. 2005; 6:56.

15. Kopp S, Warnke E, Wehland M, Aleshcheva G, Magnusson NE, Hemmersbach R, Corydon TJ, Bauer J, Infanger M, Grimm D. Mechanisms of three-dimensional growth of thyroid cells during long-term simulated microgravity. Sci Rep. 2015; 5:16691.

16. Liu J, Hu G, Chen D, Gong AY, Soori GS, Dobleman TJ, Chen XM. Suppression of SCARA5 by Snaill is essential for EMT-associated cell migration of A549 cells. Oncogenesis. 2013;2:e73.

17. Chen CM, Sun LL, Fang RM, Lin LZ. YiQi Chu Tan Recipe Inhibits Epithelial Mesenchymal Transition of A549. Cells under Hypoxia. Cell Mol Biol (Noisy-le-grand). 2016; 62:10-5.

18. Huang Q, Han J, Fan J, Duan L, Guo M, Lv Z, Hu G, Chen L, Wu F, Tao X, Xu J, Jin Y. IL-17 induces EMT via Stat3 in lung adenocarcinoma. Am J Cancer Res. 2016; 6:440-51. 
19. Acloque H, Adams MS, Fishwick K, Bronner-Fraser M, Nieto MA. Epithelial-mesenchymal transitions: the importance of changing cell state in development and disease. J Clin Invest. 2009; 119:1438-49.

20. Suzuki A, Matsushima K, Makinoshima H, Sygano S, Kohno T, Tsuchihara K, Suzyki K. Single-cell analysis of lung adenocarcinoma cell lines reveals diverse expression patterns of individual cells invoked a moleculer target during treatment. Genome Biol. 2015; 16:66.

21. Zhu Y, Tan J, Xie H, Wang J, Meng X, Wang R. HIF-1 $\alpha$ regulates EMT via the Snail and $\beta$-catenin pathways in paraquat poisoning-induced early pulmonary fibrosis. J Cell Mol Med. 2016; 20:688-97.

22. Verras M, Papandreou I, Lim AL, Denko NC. Tumor hypoxia blocks Wnt processing and secretion through the induction of endoplasmic reticulum stress. Mol Cell Biol. 2008; 28:7212-24.

23. Yao YH, Cui Y, Qiu XN, Zhang LZ, Zhang W, Li H, Yu JM. Attenuated LKB1-SIK1 signaling promotes epithelialmesenchymal transition and radioresistance of non-small cell lung cancer cells. Chin J Cancer. 2016; 35:50.

24. Li Z, Wang X, Li W, Wu L, Chang L, Chen H. miRNA-124 modulates lung carcinoma cell migration and invasion. Int J Clin Pharmacol Ther. 2016; 54:603-12.

25. Da C, Liu Y, Zhan Y, Liu K, Wang R. Nobiletin inhibits epithelial-mesenchymal transition of human non-small cell lung cancer cells by antagonizing the TGF- $\beta 1 / \mathrm{Smad} 3$ signaling pathway. Oncol Rep. 2016; 35:2767-74.

26. Sun S, Ning X, Zhang Y, Lu Y, Nie Y, Han S, Liu L, Du R, Xia L, He L, Fan D. Hypoxia-inducible factor-1alpha induces Twist expression in tubular epithelial cells subjected to hypoxia, leading to epithelial-to-mesenchymal transition. Kidney Int. 2009; 75:1278-87.

27. Chen Z, Zhu Y, Dong Y, Zhang P, Han X, Jin J, Ma X. Overexpression of TrpC5 promotes tumor metastasis via the HIF-1 $\alpha$-Twist signaling pathway in colon cancer. Clin Sci (Lond). 2017; 131:2439-2450.

28. Chen S, Chen JZ, Zhang JQ, Chen HX, Yan ML, Huang L, Tian YF, Chen YL, Wang YD. Hypoxia induces TWIST-activated epithelial-mesenchymal transition and proliferation of pancreatic cancer cells in vitro and in nude mice. Cancer Lett. 2016; 383:73-84.

29. Chen SY, Teng SC, Cheng TH, Wu KJ. miR-1236 regulates hypoxia-induced epithelial-mesenchymal transition and cell migration/invasion through repressing SENP1 and HDAC3. Cancer Lett. 2016; 378:59-67.

30. Wei L, Sun JJ, Cui YC, Jiang SL, Wang XW, Lv LY, Xie L, Song XR. Twist may be associated with invasion and metastasis of hypoxic NSCLC cells. Tumour Biol. 2016; 37:9979-87.

31. Cho KH, Yu SL, Cho DY, Park CG, Lee HY. Breast cancer metastasis suppressor 1 (BRMS1) attenuates
TGF- $\beta 1$-induced breast cancer cell aggressiveness through downregulating HIF-1 $\alpha$ expression. BMC Cancer. 2015; 15:829.

32. Yang MH, Wu MZ, Chiou SH, Chen PM, Chang SY, Liu CJ, Teng SC, Wu KJ. Direct regulation of TWIST by HIF-1alpha promotes metastasis. Nat Cell Biol. 2008; 10:295-305.

33. Mandic A, Hansson J, Linder S, Shoshan MC. Cisplatin induces endoplasmic reticulum stress and nucleusindependent apoptotic signaling. J Biol Chem. 2003; 278:9100-6.

34. Dong P, Ihira K, Hamada J, Watari H, Yamada T, Hosaka M, Hanley SJ, Kudo M, Sakuragi N. Reactivating p53 functions by suppressing its novel inhibitor iASPP: a potential therapeutic opportunity in p53 wild-type tumors. Oncotarget. 2015; 6:19968-75. https://doi.org/10.18632/ oncotarget. 4847.

35. Jiang FZ, He YY, Wang HH, Zhang HL, Zhang J, Yan XF, Wang XJ, Che Q, Ke JQ, Chen Z, Tong H, Zhang YL, Wang FY, et al. Mutant p53 induces EZH2 expression and promotes epithelial-mesenchymal transition by disrupting p68-Drosha complex assembly and attenuating miR-26a processing. Oncotarget. 2015; 6:44660-74. https://doi. org/10.18632/oncotarget.6350.

36. Hollstein M, Sidransky D, Vogelstein B, Harris CC. p53 mutations in human cancers. Science. 1991; 253:49-53.

37. Campbell TM, Main MJ, Fitzgerald EM. Functional expression of the voltage-gated $\mathrm{Na}^{+}$-channel Nav1.7 is necessary for EGF-mediated invasion in human non-small cell lung cancer cells. J Cell Sci. 2013; 126:4939-49.

38. Chen KY, Chen CC, Tseng YL, Chang YC, Chang MC. GCIP functions as a tumor suppressor in non-small cell lung cancer by suppressing Id1-mediated tumor promotion. Oncotarget. 2014; 5:5017-28. https://doi.org/10.18632/ oncotarget.2075.

39. Liu G, Shuman MA, Cohen RL. Co-expression of urokinase, urokinase receptor and PAI-1 is necessary for optimum invasiveness of cultured lung cancer cells. Int $\mathbf{J}$ Cancer. 1995; 60:501-6.

40. Fraser SP, Hemsley F, Djamgoz MB. Caffeic acid phenethyl ester: Inhibition of metastatic cell behaviours via voltagegated sodium channel in human breast cancer in vitro. Int $\mathrm{J}$ Biochem Cell Biol. 2016; 71:111-8.

41. Ogasawara M, Otani M, Takano M, Shudou M, Inaba Y, Nirasawa S, Takahashi S, Kiyoi T, Tanaka Y, Kameda K, Kunugita N, Maeyama K, Sano K, et al. The protective role of protein L-isoaspartyl (D-aspartate) O-methyltransferase for maintenance of mitochondrial morphology in A549 cell. Exp Lung Res. 2016; 21:1-18.

42. Schmalhofer O, Brabletz S, Brabletz T. E-cadherin, betacatenin, and ZEB1 in malignant progression of cancer. Cancer Metastasis Rev. 2009; 28:151-66. 
43. Iwatsuki $\mathrm{M}$, Mimori $\mathrm{K}$, Yokobori $\mathrm{T}$, Ishi $\mathrm{H}$, Beppu $\mathrm{T}$, Nakamori S, Baba H, Mori M. Epithelial-mesenchymal transition in cancer development and its clinical significance. Cancer Sci. 2010; 101:293-9.
44. Hitz C, Wurst W, Kuhn R. Conditional brain-specific knockdown of MAPK using Cre/loxP regulated interference. Nucleic Acids Res. 2007; 35:e90. 